\title{
Relationship and integrated development of low-carbon economy, food safety, and agricultural mechanization
}

\author{
Weijuan $\mathrm{Li}^{1}$ • Pengcheng Zhang ${ }^{1}$ \\ Received: 14 April 2021 / Accepted: 12 July 2021 / Published online: 17 July 2021 \\ (C) The Author(s), under exclusive licence to Springer-Verlag GmbH Germany, part of Springer Nature 2021
}

\begin{abstract}
The organic integration of food security and agricultural mechanization has become a challenge to realize a low-carbon economy, which helps promote carbon peaking and carbon neutralization. In this work, a simultaneous equation model has developed to analyze the relationship between food security, agricultural automation, and agricultural carbon emissions in China. The ordinary least square method was used to verify the method. The logarithmic mean Divisia index decomposition was used to decompose further the influencing factors of agricultural carbon emissions. Results show that the organic coupling of a low-carbon economy, food security, and agricultural mechanization positively affects environmental protection. In which, unit fertilizer usage and crop sown area have the greatest impact on carbon emission intensity, followed by agricultural diesel fuel and agricultural plastic film. It is worth noting that the bottom line of the grain sown area cannot be touched. It is a prerequisite for ensuring grain production. Finally, this paper presents suggestions based on China's achievements, where the top-level design is crucial.
\end{abstract}

Keywords Low-carbon economy $\cdot$ Food security $\cdot$ Agricultural mechanization $\cdot$ Scientific and technological innovation

\section{Introduction}

Early-stage agricultural development relied on a large investment in chemical fertilizers, pesticides, and other chemicals. While improving production efficiency, it neglected the protection of the ecological environment, even the energy (Wang et al. 2019; Liu et al. 2020). In 2018, Rome-FAO pointed out at the World Soil Day celebration ceremony that about $33 \%$ of the world's soil has been degraded and continuous at an alarming rate (Clapp et al. 2018). It also mentioned that the most significant water pollution source was not cities (e.g., traffic (Mao et al. 2021)) or industries (e.g., exhaust fumes or oil leakage (Qin et al. 2020)) but agriculture. In agricultural production, excessive fertilizers, pesticides, and plastic film have caused the continuous decline of cultivated land quality.

Responsible Editor: Ilhan Ozturk

Weijuan Li

liweijuan666@163.com

1 Department of grammar and economic management, Shandong Institute of Petroleum and Chemical Technology, Dongying 257061, China
These carbon sources remain in cultivated land soil, causing serious agricultural non-point source pollution (Wang et al. 2021; Zhao et al. 2021). The reduction of arable land will inevitably affect food safety and the carbon balance.

The environmental issues mentioned above will cause food safety issues ( $\mathrm{Li}$ et al. 2021; Li et al. 2019a, b). Hence, food security and ecological environment protection have become the world's concern. Australian forest fire and COVID-19 have caused major instability in the global supply of agriculture since the end of 2019. From Singapore's Nanyang Sin-Chew Lianhe Zaobao, many countries began to restrict their grain exports. Food security has once again become the focus of global attention. A new survey of more than 1750 respondents from China, the UK, and the USA conducted by Mars Global Food Safety Center in 2020 shows that global consumers pay more attention to food safety than their concerns about climate change (39\%) and environmental pollution (38\%). According to the report of the world food security and nutrition released by the Food and Agriculture Organization (FAO) on July 15, 2020, nearly 690 million people may be hungry in 2019 , accounting for $8.9 \%$ of the world's total population, an increase of 10 million over 2018. The problem of food safety has been very significant. Therefore, the process of food production should correspond 
to the low-carbon economic development to promote reaching carbon peaking and carbon neutralization (Guo et al. 2020).

Given that, some institutions and scholars have studied the relationship between agriculture and carbon balance. Lal (2003) and Kindler et al. (2011) found that soil erosion and loss of soil carbon leaching significantly affected the agricultural system's carbon balance. The Intergovernmental Panel on Climate Change (IPCC) reports that $13.5 \%$ of global carbon emissions come from agricultural production activities ( $\mathrm{Li}$ et al. 2021). Woomer et al. (2004) found that the main factor leading to agricultural carbon emissions is land use mode. Dyer et al. (2010) used the fossil energy consumption and carbon emission model and the economy and carbon emission model to calculate Canada's carbon emission due to corn production. Gao et al. (2019) found that the global cropland is experiencing significant eco-environmental changes. They also discussed the role of agricultural greening in the global environment and climate change. In the 1960s, Green Revolution proposed including cultivating high-yield crop varieties, increasing fertilizers, pesticides, machinery, and optimal irrigation applications. The goal is to improve crop productivity under the limited availability of arable land, which had a positive impact on environmental protection and food safety (Pingali 2012; Xu et al. 2021). The conclusion can be drawn from the previous studies. The working efficiency of agricultural machinery can be improved with the continuous improvement of agricultural technology, thereby reducing the carbon emissions of agricultural machinery. In addition, the use of clean energy can reduce the use of chemical fertilizers to decompose carbon emissions.

Global climate change and increasing population lead to challenges on food security globally. The popularization of agricultural mechanization and related activities could improve agricultural production efficiency to address these challenges (Belton et al. 2021; Jiang et al. 2020). However, agricultural mechanization intensifies the demand for agricultural diesel and gasoline, which leads to many carbon emissions and air pollution. Moreover, excessive fertilizers, pesticides, and plastic film have aggravated carbon emissions and cause the continuous decline of cultivated land quality. Therefore, it is necessary to explore the impact of agricultural mechanization on food security and low-carbon economic development to secure food production and develop low-carbon agriculture.

China is the largest grain producer in the world. In 2020, China's total grain output will reach 669.5 billion kg, increasing by $0.9 \%$ over the previous year. At the same time, China has the largest population and is also the most extensive food market (National Bureau of Statistics of China 2020a, b). In 2017, the Chinese government issued the opinions on innovating the system and mechanism to promote the green development of agriculture, which proposed strengthening the construction of major ecological projects to ensure national food security, resource security, and ecological security. The premise of agricultural growth is to deal with the relationship between resources, environment, and development. Agricultural total factor productivity (TFP) growth will be significantly overestimated if ignoring environmental constraints. TFP refers to the comprehensive productivity of the production unit as each factor in the system. In the same year, the Chinese government put forward an urgent request to increase total factor productivity. At present, the literature on food security focuses on the supply and production of food, and the research on ecological environment mainly focuses on industry. The promotion of agricultural mechanization is an important way to improve food production, but it will also increase carbon emissions. There is limited research on the synergy effect of a low-carbon economy, food safety, and agricultural mechanization. Therefore, taking China as an example, it is of typical significance to explore a low-carbon economy by combining agricultural mechanization with food security and ecological environment protection.

The purpose of this paper expounds on the importance of food security and clarifies agricultural mechanization in improving food production in China. Then, considering the impact of agricultural mechanization on food security and low-carbon economic development makes up for the lack of overall unsustainable caused by a single consideration development. This paper constructs a simultaneous equation model and uses the least square method to test-related properties. It then uses the logarithmic mean Divisia index (LMDI) decomposition method to decompose agricultural carbon emissions (Therond et al. 2017).

\section{Method}

\section{Simultaneous equation model}

Haavelmo proposed the simultaneous equation model in 1943 to explore the relationship between economic variables (Pinfang 2004). Considering that the least square method has the advantages of the unique optimal solution, convenient solution, and good analytical properties, this work uses the least square method for testing. This study focuses on the simultaneous equation model of the relationship between agricultural mechanization, food security, and agricultural carbon emissions (Chen and Chen 2018). The specific model form is as follows:

$\left\{\begin{array}{cc}\ln A M_{i}=C_{1}+\alpha_{1} \ln A S_{i}+\beta_{1} \ln E_{i}+\varepsilon_{1 i} & a \\ \ln A S_{i}=C_{2}+\alpha_{2} \ln A M_{i}+\beta_{2} \ln E_{i}+\varepsilon_{2 i} & b \\ \ln E_{i}=C_{3}+\alpha_{3} \ln A M_{i}+\beta_{3} \ln A S_{i}+\varepsilon_{3 i} & c\end{array}\right.$

where $A M, A S$, and $E$ represent agricultural mechanization, food security, and agricultural carbon emissions, respectively; 
$C$ represents intercept; $\alpha$ and $\beta$ are undetermined coefficients of variables, respectively; ${ }^{\varepsilon} 1_{i},{ }^{\varepsilon} 1_{i}$, and ${ }^{\varepsilon} 1_{i}$ represent random variables, respectively. Using Eviews ${ }^{\circledR} 10.0$ software, ordinary least squares were used to estimate three equations in Eq. (1)

Agricultural mechanization is expressed by the power of agricultural machinery used in unit grain output (unit: $\mathrm{kW} /$ tons). Food security refers to the standard that the per capita food output defined by FAO is higher than $400 \mathrm{~kg}$, which is expressed by the per capita food output ratio to $400 \mathrm{~kg}$. Agricultural carbon emissions are expressed by agricultural carbon emissions, unit: 10,000 tons/year.

The data used in this work are from China Rural Statistical Yearbook and China Statistical Yearbook (National Bureau of Statistics of China 2020a, b). The model was tested by the goodness-of-fit test $\left(\mathrm{R}^{2}\right)$, significance test of regression parameters (t-test), and significance test of a regression equation (F-test).

\section{LMDI decomposition}

The decomposition and contribution measurement methods of carbon emission influencing factors mainly include the arithmetic mean Divisia index decomposition method (Boyd et al. 1987), Laspeyres decomposition method (Jenne and Cattell 1983), and LMDI decomposition method (Ang et al. 1998). The first two decomposition methods cannot decompose multiple factors simultaneously. So, the residual value after decomposition is relatively large. Compared with the first two decomposition methods, the LMDI decomposition method has the advantages of complete decomposition, no residual, and easy to use. Existing studies have analyzed the influencing factors of carbon emissions from the national (Hatzigeorgiou et al. 2008), regional (Liu et al. 2012), and industry levels. Thus, this work uses the LMDI decomposition method to analyze the influencing factors of China's agricultural carbon emissions. From the perspective of integrating a low-carbon economy, food security, and agricultural mechanization, the influencing factors are decomposed into carbon emission intensity, agricultural machinery utilization rate, and total grain output. The decomposition of agricultural carbon emissions is as follows:

$E=\sum_{i} E_{i}=\sum_{i} \frac{T_{i} \delta_{i}}{M} \cdot \frac{M}{P} \cdot P=\sum_{i} S_{i} \cdot I \cdot P$

where $E$ is total carbon emissions (unit: 10,000 tons); $E_{i}$ is carbon emissions from the $i$-th carbon source (unit: 10,000 tons); $P$ is total grain output, unit: ten thousand tons; $\mathrm{M}$ is the total power of agricultural machinery (unit: 10,000 kW); $S_{i}=\frac{T_{i} \delta_{i}}{M}$; and the $I$ carbon source is converted to the carbon emission intensity per unit of agricultural machinery power (unit: tons/kW, $i=1,2,3,4,5$, and 6 , representing agricultural fertilizer, pesticide, agricultural diesel, agricultural plastic film, the planting area of crops, and agricultural irrigation area, respectively). The high-carbon emission intensity depends on the low-carbon emission reduction technology level; the low-carbon emission intensity corresponds to the high-carbon emission reduction technology level. $I=\frac{M}{P}$ indicates the utilization rate of agricultural machinery (unit: $\mathrm{kW} /$ tons). The utilization rate of agricultural machinery becomes higher with agricultural cultivation, sowing, and harvesting.

Based on the decomposition idea of LMDI, the difference in agricultural carbon emissions in the T-year (reporting period) and the 0 -year (base period) can be decomposed into the change values brought by three influencing factors the residual value of 0 . There are two kinds of models, i.e., additive model and multiplicative model:

$\Delta E=E^{T}-E^{0}=\Delta E_{S}+\Delta E_{I}+\Delta E_{P}$

$D=\frac{E^{T}}{E^{0}}=D_{S} \times D_{I} \times D_{P}$

where $\Delta E$ is growth of agricultural carbon emissions (unit: 10,000 tons); $D$ is growth rate of agricultural carbon emissions; $E^{T}$ and $E^{0}$ are agricultural carbon emissions in year $t$ and year 0 (unit: 10,000 tons); $\Delta E_{S}, \Delta E_{I,}$ and $\Delta E_{P}$ are the contribution values of carbon emission intensity, utilization rate of agricultural machinery and total grain output to the growth of agricultural carbon emission in turn (unit: 10,000 tons); $D_{S}$, $D_{I}$, and $D_{P}$ are the contribution rates of carbon emission intensity, utilization rate of agricultural machinery, and total grain output to the growth rate of agricultural carbon emission. The calculation formula of each index in Eq. (3) and Eq. (4) is as follows:

$$
\begin{aligned}
\Delta E_{S} & =\sum_{i} \frac{E_{i}^{t}-E_{i}^{0}}{L N\left(E_{i}^{t} / E_{i}^{0}\right)} \cdot \mathrm{L} N \frac{S_{i}^{t}}{S_{i}^{0}}, \quad D_{S} \\
& =\exp \left(\sum_{i} \frac{E_{i}^{t}-E_{i}^{0}}{L N\left(E_{i}^{t} / E_{i}^{0}\right)} \cdot L N \frac{S_{i}^{t}}{S_{i}^{0}} /\left(\frac{E^{t}-E^{0}}{L N\left(E^{t} / E^{0}\right)}\right)\right) \\
\Delta E_{I} & =\sum_{i} \frac{E_{i}^{t}-E_{i}^{0}}{L N\left(E_{i}^{t} / E_{i}^{0}\right)} \cdot L N \frac{I_{i}^{t}}{I_{i}^{0}}, \quad D_{I} \\
& =\exp \left(\sum_{i} \frac{E_{i}^{t}-E_{i}^{0}}{L N\left(E_{i}^{t} / E_{i}^{0}\right)} \cdot L N \frac{I_{i}^{t}}{I_{i}^{0}} /\left(\frac{E^{t}-E^{0}}{L N\left(E^{t} / E^{0}\right)}\right)\right) \\
\Delta E_{P} & =\sum_{i} \frac{E_{i}^{t}-E_{i}^{0}}{L N\left(E_{i}^{t} / E_{i}^{0}\right)} \cdot L N \frac{P_{i}^{t}}{P_{i}^{0}}, \quad D_{P} \\
& =\exp \left(\sum_{i} \frac{E_{i}^{t}-E_{i}^{0}}{L N\left(E_{i}^{t} / E_{i}^{0}\right)} \cdot L N \frac{P_{i}^{t}}{P_{i}^{0}} /\left(\frac{E^{t}-E^{0}}{L N\left(E^{t} / E^{0}\right)}\right)\right)
\end{aligned}
$$


In China, agricultural carbon emissions can be divided into six types of carbon sources: agricultural fertilizer, pesticide, agricultural diesel, agricultural plastic film, crop planting area, and agricultural irrigation area (Li et al. 2011). The total agricultural carbon emissions are calculated using the emission coefficient of the corresponding carbon source and carbon source emissions. Li et al. (2011) have sorted out the sources of carbon emission coefficients as follows:

$\mathrm{E}=\sum \mathrm{E}_{\mathrm{i}}=\sum \mathrm{T}_{\mathrm{i}} \delta_{\mathrm{i}}$

where $E$ is the agricultural emissions; $E_{i}$ is the carbon emissions of various carbon sources $(i=1,2, \ldots, 6) ; \mathrm{T}_{i}$ is the amount of various carbon emission sources; and $\delta_{i}$ is the carbon emission coefficient of various carbon emission sources.

\section{Results}

\section{Agricultural carbon emission}

The specific data are shown in Table 1. Among them, agricultural fertilizer, pesticide, agricultural diesel consumption, and crop planting area data are from China Rural Statistical Yearbook (2007-2020). The agricultural plastic film consumption and agricultural irrigation area are from China Statistical Yearbook (2007-2020).

From Fig. 1, China's total agricultural carbon emissions increase from 121.628 million tons in 2006 to 143.046 million tons in 2015 and then decrease by year. By 2019, China's total agricultural carbon emissions decreased to 132.786 million tons. The carbon emission per 10,000 tons of grain production has gradually decreased from 24.42 million tons in 2006 to 20 million tons in 2019. It can be seen that the carbon emission of China's agriculture has been well controlled. The reduction of carbon emission per unit grain is due to the influence of many factors. The China government has increased policy support for agricultural development and environmental protection. The 13th Five-Year Comprehensive Work Plan for energy conservation and emission reduction promotes energy structure optimization and promotes high efficiency and energy conservation in agriculture.

\section{Food security}

The per capita grain output reflects the food supply security of a country. From 2006 to 2015, China's per capita grain output increased steadily, from $380 \mathrm{~kg}$ in 2006 to $482 \mathrm{~kg}$ in 2015 (Table 2). In 2008, it reached the internationally recognized food security line of $400 \mathrm{~kg}$ per capita food production. Since 2016, the per capita grain production has shown a slight downward trend. From 2016 to 2019, China's per capita grain production is $479 \mathrm{~kg}, 477 \mathrm{~kg}, 472 \mathrm{~kg}$, and $475 \mathrm{~kg}$. Although it is higher than the internationally recognized food safety line, it needs to be paid attention to. The main reasons are the decrease of yield per unit area and the decrease of planting area. But the output per unit area has increased steadily. The output per unit area in 2019 is 1.2 times that in 2006, mainly due to the use of agricultural machinery and the adjustment of agricultural planting structure.

\section{Impact of agricultural mechanization on food security}

The main level of agricultural mechanization is the total power of agricultural machinery. From 2006 to 2015, the total power of China's agricultural machinery increased by year, reaching the highest value of 1117.2807 million $\mathrm{kW}$ in 2015, which was $54.06 \%$ higher than that of 2006 . The number of small tractors is much larger than that of large- and medium-sized agricultural tractors, with 17,030,400 and 6,072,900 in 2015. The level of agricultural mechanization is structurally unbalanced, and the industry concentration is far lower than that of developed countries in Europe and America.

Agricultural mechanization has realized the fundamental transformation from traditional agriculture to modern agriculture and greatly liberated rural labor productivity. At present, China's leading food crops, such as wheat, have basically realized the whole agricultural mechanization production process. From Fig. 2, the total power and grain output of agricultural machinery reach the highest value in 2015. In 2016, the total power of agricultural machinery was
Table 1 Agricultural carbon emission sources, coefficients, and reference sources

\begin{tabular}{lll}
\hline Carbon emission source & Carbon emission coefficient & Sources \\
\hline Agricultural fertilizer & $0.8956(\mathrm{~kg} / \mathrm{kg})$ & West and Marland (2002) \\
Pesticides & $4.9341(\mathrm{~kg} / \mathrm{kg})$ & Zhi and Gao (2009) \\
Agricultural diesel oil & $0.5927(\mathrm{~kg} / \mathrm{kg})$ & Li et al. (2011) \\
Agricultural plastic film & $5.1800(\mathrm{~kg} / \mathrm{kg})$ & Li et al. (2011) \\
Planting area of crops & $312.6000\left(\mathrm{~kg} / \mathrm{hm}^{2}\right)$ & Wu et al. (2007) \\
Agricultural irrigation area & $25.0000\left(\mathrm{~kg} / \mathrm{hm}^{2}\right)$ & Dubey and Lal (2009) \\
\hline
\end{tabular}


Fig. 1 Trend of agricultural carbon emissions and carbon emissions per unit grain output from 2006 to 2019 (National Bureau of Statistics of China 2020a)

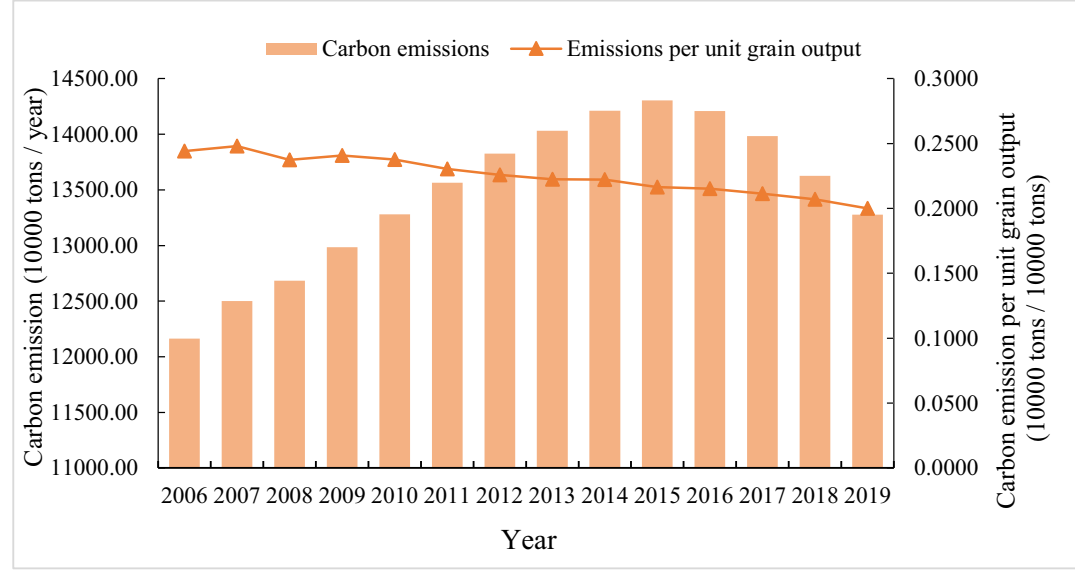

$97,245,590 \mathrm{~kW}$, which was significantly lower than that in 2015 , with a decline of $144,824,800 \mathrm{~kW}$. Yang et al. (2013) also confirmed the effect of agricultural mechanization on grain production by analyzing China's agricultural data. Other scholars used the difference-in-differences estimation to measure the obvious promotion effect of agricultural mechanization on grain output ( $\mathrm{Wu} 2014)$.

Next, the quantitative analysis method will calculate the relationship between food safety and low-carbon economy and agricultural mechanization and decompose the influencing factors of agricultural carbon sources.

\section{The synergy effect of food security, low-carbon economy, and agricultural mechanization}

Table 3 shows the regression analysis results and includes the coefficients of the variables in the equation, the coefficient of determination of fitting, and the $\mathrm{F}$ value. The $\mathrm{R}^{2}$ of equation a in Eq. (1) is 0.4004 , which indicates that the ability of food security and agricultural carbon emissions to explain the change of agricultural mechanization is limited. The p-value of the F-test was more than 5\%, which indicated that the overall linear regression equation established with food security and agricultural carbon emissions as independent variables and agricultural mechanization as dependent variables had little significance. The $\mathrm{R}^{2}$ of equation $\mathrm{b}$ in Eq. (1) is 0.8786 , which shows that the linear relationship is significant. Agricultural mechanization and agricultural carbon emissions can explain most of the changes in food security. The p-value of the F-test was less than $1 \%$, which indicated that the linear regression equation established with agricultural mechanization and agricultural carbon emissions as independent variables and food security as dependent variables was meaningful. The p-value of the variable coefficient t-test of agricultural mechanization was more than 5\%, which indicated that agricultural mechanization could not explain food security well at
Table 2 China's grain output (2006-2019)

\begin{tabular}{lllll}
\hline Year & $\begin{array}{l}\text { Total grain output } \\
(10,000 \text { tons })\end{array}$ & $\begin{array}{l}\text { Grain sown } \\
\text { area } \\
(1000 \mathrm{HA})\end{array}$ & $\begin{array}{l}\text { Yield per unit sown area }(10,000 \\
\text { tons/1000 HA })\end{array}$ & $\begin{array}{l}\text { Grain output per } \\
\text { capita } \\
(\mathrm{kg})\end{array}$ \\
\hline 2006 & $49,804.23$ & 104,958 & 0.4745 & 380 \\
2007 & $50,413.85$ & 105,999 & 0.4756 & 383 \\
2008 & $53,434.29$ & 107,545 & 0.4969 & 403 \\
2009 & $53,940.86$ & 110,255 & 0.4892 & 405 \\
2010 & $55,911.31$ & 111,695 & 0.5006 & 418 \\
2011 & $58,849.33$ & 112,980 & 0.5209 & 438 \\
2012 & $61,222.62$ & 114,368 & 0.5353 & 453 \\
2013 & $63,048.2$ & 115,908 & 0.5440 & 464 \\
2014 & $63,964.83$ & 117,455 & 0.5446 & 469 \\
2015 & $66,060.27$ & 118,963 & 0.5553 & 479 \\
2016 & $66,043.51$ & 119,230 & 0.5539 & 477 \\
2017 & $66,160.72$ & 117,989 & 0.5607 & 472 \\
2018 & $65,789.22$ & 117,038 & 0.5621 & 475 \\
2019 & $66,384.34$ & 116,064 & 0.5720 & \\
\hline
\end{tabular}


Fig. 2 China's agricultural machinery total power and grain output from 2006 to 2019 (National Bureau of Statistics of China 2020b)

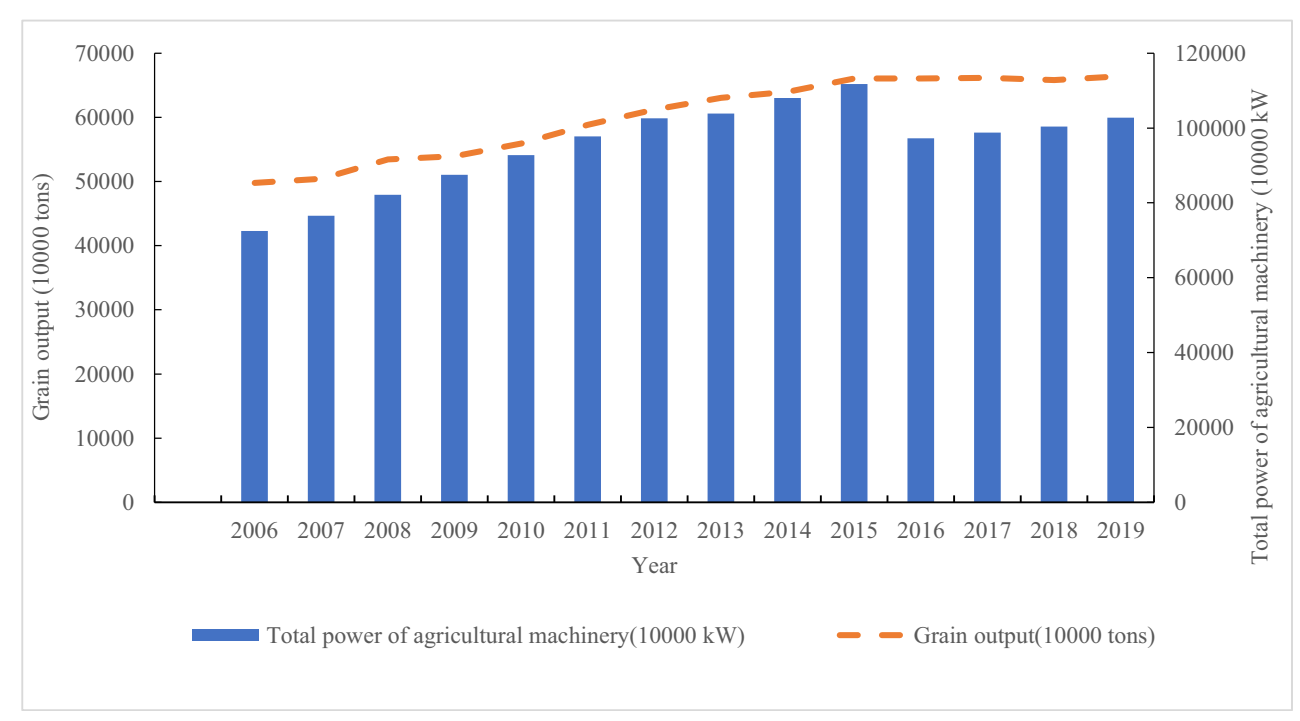

the significant level of 5\%. The coefficient of the agricultural carbon emissions t-test $\mathrm{p}$-value is less than $5 \%$, indicating that agricultural carbon emissions can explain food security well. The linear regression equation and the coefficient of variables indicate agricultural mechanization, and agricultural carbon emissions jointly improve food security. The $\mathrm{R}^{2}$ of equation c in Eq. (1) is 0.8977, which shows that the linear relationship is significant. Agricultural mechanization and food security can better explain agricultural carbon emissions. The p-value of the F-test is less than $1 \%$, which indicates that the linear regression equation established with agricultural mechanization and food security as independent variables and agricultural carbon emissions as dependent variables is meaningful. Agricultural mechanization and food security jointly promote agricultural carbon emissions. The t-test $\mathrm{p}$-value of each variable coefficient is less than $5 \%$, indicating that agricultural mechanization and food security can explain agricultural carbon emissions. Combined with the linear regression equation and the coefficient of variables, agricultural mechanization and food security jointly promote increased agricultural carbon emissions, and both are positive.

In conclusion, equation b in Eq. (1) shows that the main ways to improve food security are to increase the total power of agricultural machinery per unit grain yield and reduce the carbon emission per unit grain yield. Equation b in Eq. (1)

Table 3 Estimation of OSL model

\begin{tabular}{llllll}
\hline Eq. (1) & $C$ & $\alpha$ & $\beta$ & $\mathrm{R}^{2}$ & F value \\
\hline Equation a & $-14.1468^{* *}$ & $-0.6898^{*}$ & $1.5434^{* *}$ & 0.4004 & 3.6722 \\
Equation b & $16.0467^{* * * *}$ & $0.3566^{*}$ & $1.7154^{* * *}$ & 0.8786 & 39.7927 \\
Equation c & $9.3490^{* * *}$ & $0.2362^{* *}$ & $0.5080^{* * *}$ & 0.8977 & 48.2557 \\
\hline
\end{tabular}

$*, * *, * * *$ indicate that they have passed $1 \%, 5 \%$, and $10 \% \mathrm{t}$-test level, respectively, and they are significant at this level shows that the main ways to reduce agricultural carbon emissions are to reduce the total power of agricultural machinery per unit grain yield and reduce food security. However, food security affects people worldwide. So, it is necessary to implement the national food security strategy, and food production cannot be arbitrarily reduced. It is not feasible to reduce agricultural carbon emissions by reducing agricultural mechanization and food security. Also, it is necessary to reduce agricultural carbon emissions on the premise of ensuring food security. Therefore, the agricultural carbon emission factors will be further decomposed to find a suitable way.

\section{Decomposition results of influencing factors of agricultural carbon emissions}

Table 4 shows the carbon emission intensities of six carbon sources converted to the unit power of agricultural machinery, expressed in S1-S6, respectively, where $\mathrm{Si}$ is the carbon emission intensity of the $i$-th carbon source converted to the unit power of agricultural machinery and $i=1,2,3,4,5,6$, representing agricultural fertilizer, pesticide, agricultural diesel, agricultural plastic film, the planting area of crops, and agricultural irrigation area, respectively. In 2006, the total carbon emission intensity of six types of carbon sources was 0.168 , with S1 value of 0.061 and S5 value of 0.066 , accounting for the largest proportion, ranking the top two among the six carbon sources. The total carbon emission intensity of six carbon sources in 2019 is 0.129 , which is 0.039 lower than in 2006. The values of S1 and S5 decreased to 0.047 and 0.050 , respectively. Among the six types of carbon sources, chemical fertilizer per unit and the planting area of crops significantly impact the carbon emission intensity.

Table 5 shows the utilization of agricultural mechanization from 2006 to 2019. With the development of agricultural modernization, the overall utilization rate of agricultural 
Table 4 Carbon emission intensity (unit: tons $/ \mathrm{kW}$ )

\begin{tabular}{|c|c|c|c|c|c|c|c|c|c|c|c|c|c|c|}
\hline Year & 2006 & 2007 & 2008 & 2009 & 2010 & 2011 & 2012 & 2013 & 2014 & 2015 & 2016 & 2017 & 2018 & 2019 \\
\hline S1 & 0.061 & 0.060 & 0.057 & 0.055 & 0.054 & 0.052 & 0.051 & 0.051 & 0.050 & 0.048 & 0.055 & 0.053 & 0.050 & 0.047 \\
\hline S2 & 0.010 & 0.010 & 0.010 & 0.010 & 0.009 & 0.009 & 0.009 & 0.009 & 0.008 & 0.008 & 0.009 & 0.008 & 0.007 & 0.007 \\
\hline S3 & 0.013 & 0.013 & 0.013 & 0.012 & 0.012 & 0.012 & 0.012 & 0.012 & 0.012 & 0.012 & 0.014 & 0.013 & 0.013 & 0.012 \\
\hline S4 & 0.016 & 0.016 & 0.014 & 0.013 & 0.013 & 0.012 & 0.012 & 0.012 & 0.012 & 0.012 & 0.013 & 0.013 & 0.012 & 0.011 \\
\hline S5 & 0.066 & 0.062 & 0.059 & 0.056 & 0.053 & 0.051 & 0.049 & 0.049 & 0.048 & 0.047 & 0.054 & 0.053 & 0.052 & 0.050 \\
\hline S6 & 0.002 & 0.002 & 0.002 & 0.002 & 0.002 & 0.002 & 0.002 & 0.002 & 0.001 & 0.001 & 0.002 & 0.002 & 0.002 & 0.002 \\
\hline Total & 0.168 & 0.163 & 0.154 & 0.148 & 0.143 & 0.139 & 0.135 & 0.135 & 0.132 & 0.128 & 0.146 & 0.142 & 0.136 & 0.129 \\
\hline
\end{tabular}

$\mathrm{S} i$ is the carbon emission intensity of the $i$-th carbon source converted to the unit power of agricultural machinery; $i=1,2,3,4,5,6$, representing agricultural fertilizer, pesticide, agricultural diesel, agricultural plastic film, the planting area of crops, and agricultural irrigation area, respectively

machinery shows an increasing trend by improving food production demand. In 2015, the utilization rate of agricultural mechanization reached the highest value of 1.691, and the grain output also achieved the highest value that year.

Table 6 and Fig. 3 show decompose results of the influencing factors and change agricultural carbon emissions from 2006 to 2019 . The results are (1) that the increment value of agricultural carbon emissions in China was the largest in 2015 from the carbon emission trend. In 2015, the added value was 21.4174 million tons, and the growth rate of carbon emissions gradually decreased after 2016, indicating that China's agricultural carbon emissions have been controlled to a certain extent. (2) From the perspective of carbon emission intensity, the change of carbon emission intensity from 2006 to 2019 significantly promotes agricultural carbon emission reduction. Carbon source consumption shows a downward trend and has a good effect on agricultural carbon source control. (3) From the perspective of the utilization rate of agricultural machinery, the utilization rate of machinery in 2006-2019 increased the agricultural carbon emissions. This is because expanding the scale of agricultural machinery will increase fuel and power consumption, e.g., increasing the demand for diesel, which leads to an increase in the total carbon emissions. (4) From the perspective of total grain output, the growth of agricultural carbon emissions in 2006-2019. This is because using fertilizer and other carbon sources in the production process increases the total consumption of various carbon sources and total carbon emissions.

Table 5 Utilization rate of agricultural mechanization (unit: $\mathrm{kW} /$ tons)

\begin{tabular}{llllllll}
\hline Year & 2006 & 2007 & 2008 & 2009 & 2010 & 2011 & 2012 \\
\hline Utilization rate & 1.456 & 1.519 & 1.538 & 1.622 & 1.659 & 1.661 & 1.675 \\
Year & 2013 & 2014 & 2015 & 2016 & 2017 & 2018 & 2019 \\
Utilization rate & 1.648 & 1.689 & 1.691 & 1.472 & 1.493 & 1.526 & 1.548 \\
\hline
\end{tabular}

\section{Discussion and recommendations}

In the early stage of agricultural development, it overemphasized production efficiency and ignored ecological environment protection. The rising in agricultural carbon emissions has caused increasingly serious environmental pollution, which has attracted the world's attention. However, food security concerns the well-being of people worldwide and is the bottom line to be followed in the development of agriculture. To effectively improve agricultural productivity and ensure food production is an important way to maintain food security, in which, the popularization of agricultural mechanization is an important way to improve food security. However, the use of agricultural machinery and equipment will also increase gasoline and diesel consumption, thus increasing carbon emissions. To reduce the carbon emissions in agricultural mechanization, it is important to improve agricultural machinery's total power to increase the yield of unit grain area combined with scientific and technological innovation. In this section, the recommendations are provided based on China's achievement in increasing production and reducing carbon emission.

\section{Improving the policy of ecological agriculture and agricultural machinery application}

Due to its large population, China has always attached great importance to food security ( $\mathrm{Li}$ et al. 2019a, b). To reach the international food safety standard, China introduced the agricultural machinery purchase subsidy policy in 2004 to give direct subsidies to those who purchase agricultural machinery. Also, the law on promoting agricultural mechanization was officially implemented in China. The promulgation of these two policies promoted agricultural mechanization, accelerated modern agriculture, and made China's grain output increase significantly. In 2008, the food security line reached the standard. However, with the increase of carbon emissions, agricultural, environmental pollution has become increasingly 
Table 6 Impact of agricultural carbon emissions in 2007-2019 (compared with data in 2006)

\begin{tabular}{|c|c|c|c|c|c|c|c|c|}
\hline \multirow[t]{2}{*}{ Year } & \multicolumn{2}{|c|}{$\begin{array}{l}\text { Carbon emission } \\
\text { growth }\end{array}$} & \multicolumn{2}{|c|}{ Carbon intensity } & \multicolumn{2}{|c|}{$\begin{array}{l}\text { Utilization rate of } \\
\text { agricultural machinery }\end{array}$} & \multicolumn{2}{|c|}{ Total grain output } \\
\hline & $\begin{array}{l}\Delta E(10,000 \\
\text { tons })\end{array}$ & $D$ & $\begin{array}{l}\Delta E_{S}(10,000 \\
\text { tons })\end{array}$ & $D_{S}$ & $\begin{array}{l}\Delta E_{I}(10,000 \\
\text { tons })\end{array}$ & $D_{I}$ & $\begin{array}{l}\Delta E_{P}(10,000 \\
\text { tons })\end{array}$ & $D_{P}$ \\
\hline 2007 & 338.19 & 1.03 & -334.69 & 0.97 & 522.86 & 1.04 & 150.02 & 1.01 \\
\hline 2008 & 522.05 & 1.04 & $-1,032.42$ & 0.92 & 680.61 & 1.06 & 873.86 & 1.07 \\
\hline 2009 & 823.02 & 1.07 & $-1,536.14$ & 0.89 & 1356.33 & 1.11 & 1002.83 & 1.08 \\
\hline 2010 & 1118.51 & 1.09 & $-2,012.97$ & 0.86 & 1661.15 & 1.13 & 1470.33 & 1.12 \\
\hline 2011 & 1402.69 & 1.12 & $-2,430.76$ & 0.83 & 1689.34 & 1.13 & 2144.12 & 1.17 \\
\hline 2012 & 1663.77 & 1.14 & $-2,831.92$ & 0.81 & 1817.88 & 1.14 & 2677.81 & 1.22 \\
\hline 2013 & 1868.49 & 1.15 & $-2,831.43$ & 0.82 & 1618.07 & 1.12 & 3081.85 & 1.25 \\
\hline 2014 & 2048.33 & 1.17 & $-3,197.15$ & 0.80 & 1953.82 & 1.15 & 3291.67 & 1.26 \\
\hline 2015 & 2141.74 & 1.18 & $-3,562.51$ & 0.78 & 1975.99 & 1.15 & 3728.25 & 1.30 \\
\hline 2016 & 2044.91 & 1.17 & $-1,813.43$ & 0.88 & 146.45 & 1.01 & 3711.89 & 1.30 \\
\hline 2017 & $1,822.05$ & 1.15 & $-2,210.17$ & 0.85 & 326.85 & 1.02 & 3705.37 & 1.30 \\
\hline 2018 & 1464.26 & 1.12 & $-2,720.27$ & 0.82 & 600.44 & 1.04 & 3584.09 & 1.30 \\
\hline 2019 & 1115.79 & 1.09 & $-3,312.35$ & 0.78 & 776.72 & 1.06 & 3651.42 & 1.31 \\
\hline
\end{tabular}

severe. In 2015, agricultural carbon emissions reached the highest value. In 2016, China promulgated the agricultural resources and ecological environment protection project planning (2016-2020) and further promoted ecological environment protection work. After 2016, reducing total carbon emissions and carbon emissions per unit grain output shows policy guidance effectiveness. In 2018, the Chinese government comprehensively deployed agricultural ecological and environmental protection to lay a solid foundation for preventing and controlling agricultural non-point source pollution and promoting green agricultural development. The reduction of total carbon emissions and carbon emissions per unit grain output shows China's policy guidance effectiveness. Therefore, establishing correct top-level design ideas and adherence to the combination of agricultural production and green development can better guide the world to improve food security and protect the ecological environment. Evidence from recent studies also highlights the importance of top-level design (Churilov et al. 2018; Yu and $\mathrm{Wu}$ 2018). Therefore, it is recommended that countries actively establish clear policy guidance to accelerate the popularization of agricultural mechanization and control agricultural non-point source pollution. The first is to eliminate GDP preference and take green GDP as one of the performance evaluations; the second is to give farmers subsidies for the application of agricultural machinery and to clarify the attitude of agricultural machinery promotion; third, the government can provide financial support for industries in low-carbon technology and new energy R \& D to encourage the establishment of a scientific and technological innovation system; the fourth is to
Fig. 3 Contribution rate of influencing factors of agricultural carbon emissions from 2007 to 2019

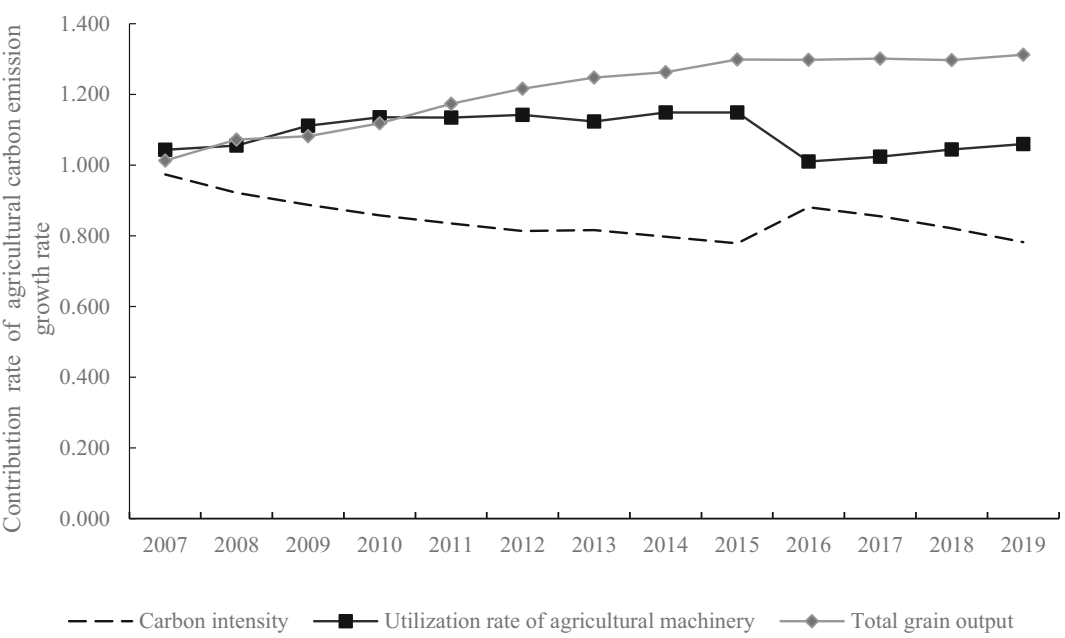


develop incentives and penal measures for the development of low-carbon agriculture and abandon high-polluting production to guide low-carbon development.

\section{Strengthening scientific and technological innovation to improve the utilization rate of agricultural machinery}

The grain sown area began to be limited with industrialization development (Wang et al. 2019). The increase of the utilization rate of agricultural machinery can improve the yield per unit grain planted area, conducive to maintaining food security. The promotion of agricultural mechanization is relatively easy in plain areas. Still, large machinery cannot be used in hilly areas due to scattered planting areas and uneven terrain, so that the utilization rate of agricultural machinery is low. Given the diversity of planting structures in hilly areas, it is necessary to increase the innovation of diversified agricultural machinery (Yin et al. 2009). It is also suggested to use the duplex operation mode widely, which can complete multiple operation projects simultaneously. On the one hand, it can reduce the auxiliary operation time. On the other hand, it can also achieve the dual reduction of fuel consumption and exhaust emissions.

\section{Strengthening the research and development of clean energy to reduce the carbon emission of agricultural mechanization}

The popularization of agricultural mechanization improves the efficiency of agricultural production ( $\mathrm{Li}$ et al. 2020). It intensifies the demand for agricultural diesel and gasoline, which leads to many carbon emissions and air pollution. Clean energy technology can reduce carbon emissions, which is the first choice of research and development. Using more solar energy, biogas, and other engines as fuel reduces power in agricultural machinery production operations to reduce emissions (Wang et al. 2018a). The use of clean energy alleviates the contradiction between agricultural machinery and the protection of the ecological environment, which is committed to addressing the two critical problems of global ecological environment protection and food safety.

\section{Improving farmers' awareness of environmental protection and optimize the use of chemical fertilizer}

Among the six carbon sources of agricultural production, chemical fertilizer and grain planting area significantly impact carbon emission intensity. As the sown area is the basis of grain production, China has proposed strictly abiding by the red line of 1,200,000 $\mathrm{km}^{2}$ of arable land in China and ensuring that the sown area of grain is stable at $110,000 \mathrm{~km}^{2}$. Therefore, we can start with chemical fertilizer to reduce carbon emissions. Secondly, a low fertilizer utilization rate has always been a problem in China's agricultural fertilization, leading to soil deterioration. The Chinese government proposed reducing the use of chemical fertilizers and pesticides and increasing organic fertilizers. Farmers are the direct users of chemical fertilizers in the process of farming. It is necessary to explain the amount of fertilizer used and its advantages and disadvantages to farmers. One is to describe the correct use of chemical fertilizer by professionals to maximize the effect of chemical fertilizer used and avoid excessive pollution. Agricultural professionals play an important role in informing and educating farmers about biofuel through teaching or extension work (Yaghoubi et al. 2019; Wang et al. 2018a, b). Finally, the state gives subsidies to guide organic fertilizer, a traditional farmyard fertilizer with less pollution.

\section{Strengthening the cultivation of high-skilled talents in colleges and universities to support the green de- velopment of agriculture}

The R \& D and application of high-tech agricultural mechanization and implementation of the low-carbon economy plan are inseparable from professionals. In addition to experts and scholars, college and university students are also important talent support for agricultural green development. Colleges and universities may strengthen the cultivation of high-skilled talents in key fields such as food engineering and the transformation of agricultural scientific and technological achievements to break the restriction of shortage of talents in key positions.

\section{Conclusions}

In this work, a least square-based method is used to investigate the relationship between agricultural mechanization, food security, and agricultural carbon emissions. The LMDI decomposition method is used to decompose the influencing factors of agricultural carbon emissions. Then, the integration relationship between low-carbon economy, food security, and agricultural mechanization in China is analyzed and discussed. Results show that the organic coupling of a low-carbon economy, food security, and agricultural mechanization positively affects environmental protection, in which unit fertilizer usage and crop sown area have the greatest impact on carbon emission intensity, followed by agricultural diesel fuel and agricultural plastic film. Finally, the subsequent development countermeasures were proposed to reference ecological environment protection and food security in developing countries in the world.

By analyzing the results, it can be concluded that the mechanized utilization can be optimized as far as possible through scientific and technological innovation, improving food 
production, reducing carbon emissions, and coordinating the integration of food security and a low-carbon economy.

Acknowledgements The authors thank the institutions that provided funding.

Author contribution W. Li drafted the initial manuscript and analyzed the data, W. Li conceptualized and designed the study, P. Zhang analyzed the data and reviewed the manuscript, and W. Li carried out the initial analyses, reviewed, and revised the manuscript. All authors approved the final manuscript.

Funding This study was supported by the following projects: the Shandong Provincial Natural Science Foundation (ZR2019QG011) and the Research Project of Teaching Reform in Undergraduate Universities of Shandong Province (M2020308).

Data availability All data generated or analyzed during this study are included in the paper.

\section{Declarations}

Ethical approval Not applicable.

Consent to participate Not applicable.

Consent to publish Not applicable.

Competing interests The authors declare no competing interests.

\section{References}

Ang BW, Zhang FQ, Choi KH (1998) Factorizing changes in energy and environmental indicators through decomposition. Energy 23:489495

Belton B, Myat TW, Zhang X, Filipski M (2021) The rapid rise of agricultural mechanization in Myanmar. Food Policy 101:102095

Boyd G, McDonald JF, Ross M, Hansont DA (1987) Separating the changing composition of US manufacturing production from energy efficiency improvements: a Divisia index approach. Energy J 8:2-6

Chen Y, Chen W (2018) A study on the relationship among agricultural mechanization industrial upgrading and agricultural carbon emission. Aust J Agric Econ 05:122-133

Churilov GI, Polischuk SD, Kuznetsov D, Borychev SN, Byshov NV, Churilov DG (2018) Agro ecological grounding for the application of metal nanopowders in agriculture. Int J Nanotechnol 15(4-5): $258-279$

Clapp J, Newell P, Brent ZW (2018) The global political economy of climate change, agriculture and food systems. J Peasant Stud 45(1): $80-88$

Dubey A, Lal R (2009) Carbon footprint and sustainability of agricultural production systems in Punjab, India, and Ohio, USA. J Crop Improv 23:332-350

Dyer JA, Kulshreshtha SN, McConkey BG, Desjardins RL (2010) An assessment of fossil fuel energy use and $\mathrm{CO}_{2}$ emissions from farm field operations using a regional level crop and land use database for Canada. Energy 35:2261-2269

Gao X, Liang S, He B (2019) Detected global agricultural greening from satellite data. Agric For Meteorol 276:107652
Guo A, Yang J, Sun W, Xiao X, Cecilia JX, Jin C, Li X (2020) Impact of urban morphology and landscape characteristics on spatiotemporal heterogeneity of land surface temperature. Sustain Cities Soc 63: 102443

Hatzigeorgiou E, Polatidis H, Haralambopoulos D (2008) Energy related $\mathrm{CO}_{2}$ emissions for Greece: decomposition analysis for 1990-2002. In 4th International Congress for South Eastern Europe Energy Efficiency and Renewable Energy Sources

Jenne CA, Cattell RK (1983) Structural change and energy efficiency in industry. Energy Econ 5:114-123

Jiang M, Hu X, Chunga J, Lin Z, Fei R (2020) Does the popularization of agricultural mechanization improve energy-environment performance in China's agricultural sector? J Clen Prod 276:124210

Kindler R, Siemens JAN, Kaiser K et al (2011) Dissolved carbon leaching from soil is a crucial component of the net ecosystem carbon balance. Glob Chang Biol 17:1167-1185

Lal R (2003) Soil erosion and the global carbon budget. Environ Int 29: $437-450$

Li B, Zhang J, Li H (2011) Research on spatial-temporal characteristics and affecting factors decomposition of agricultural carbon emission in China. China Pollut Resour Environ 8:80-86

Li C, Gao X, He BJ, Wu J, Wu K (2019a) Coupling coordination relationships between urban-industrial land use efficiency and accessibility of highway networks: evidence from Beijing-Tianjin-Hebei urban agglomeration, China. Sustainability 11:1446

Li C, Gao X, Wu J, Wu K (2019b) Demand prediction and regulation zoning of urban-industrial land: evidence from Beijing-TianjinHebei urban agglomeration, China. Environ Monit Assess 191:1-14

Li C, Wu K, Gao X (2020) Manufacturing industry agglomeration and spatial clustering: evidence from Hebei province, China. Environ Dev Sustain 22:2941-2965

Li N, Yang J, Qiao Z, Wang Y, Miao S (2021) Urban thermal characteristics of local climate zones and their mitigation measures across cities in different climate zones of China. Remote Sens 13:1468

Liu Z, Liang S, Geng Y, Xue B, Xi F, Pan Y, Zhang T, Fujita T (2012) Features, trajectories and driving forces for energy-related $\mathrm{GHG}$ emissions from Chinese mega cites: the case of Beijing, Tianjin, Shanghai and Chongqing. Energy 37:245-254

Liu J, Geng T, Wang X, Qin G (2020) Determinants of oil footprints embodied in Sino-US trade: a perspective from the globalizing world. Energies 13(15):3786

Mao Y, Qin G, Ni P, Liu Q (2021) Analysis of road traffic speed in Kunming plateau mountains: a fusion PSO-LSTM algorithm. Int J Urban Sci:1-21

National Bureau of Statistics of China (2020a) China rural statistical yearbook. China Statistical Press

National Bureau of Statistics of China (2020b) China statistical yearbook. China Statistical Press

Pinfang Z (2004). Modern econometrics. Shanhai: Shanghai University of Finance and Economics Press

Pingali PL (2012) Green revolution: impacts, limits, and the path ahead. P Natl Acad Sci USA 109:12302-12308

Qin G, Zhang P, Hou X, Wu S, Wang Y (2020) Risk assessment for oil leakage under the common threat of multiple natural hazards. Environ Sci Pollut Res 27:16507-16520

Therond O, Duru M, Roger-Estrade J, Richard G (2017) A new analytical framework of farming system and agriculture model diversities. A review Agron Sustain Dev 37(3):1-24

Wang H, Xu J, Sheng L, Liu X, Lu Y, Li W (2018a) A review on biohydrogen production technology. Int J Energy Res 42:3442-3453

Wang H, Xu J, Sheng L, Liu X (2018b) Effect of addition of biogas slurry for anaerobic fermentation of deer manure on biogas production. Energy 165:411-418

Wang H, Xu J, Liu X, Zhang D, Li L, Li W, Sheng L (2019) Effects of long-term application of organic fertilizer on improving organic 
matter content and retarding acidity in red soil from China. Soil Tillage Res 195:104382

Wang H, Xu J, Liu X, Sheng L (2021) Preparation of straw activated carbon and its application in wastewater treatment: a review. J Clean Prod 283:124671

West TO, Marland G (2002) A synthesis of carbon sequestration, carbon emissions, and net carbon flux in agriculture: comparing tillage practices in the United States. Agric Ecosyst Environ 91:217-232

Woomer PL, Tieszen LL, Tappan G, Touré A, Sall M (2004) Land use change and terrestrial carbon stocks in Senegal. J Arid Environ 59: 625-642

Wu Y L (2014) Soil and water conservation projects and national food safety: a panel difference-in-differences estimation based on Heilongjiang province. In 2014 International Conference on Management Science \& Engineering 21th Annual Conference Proceedings, IEEE, pp 2034-2041

Wu F, Li L, Zhang H, Chen F (2007) Effects of conservation tillage on net carbon flux from farmland ecosystems. Chinese J Ecol 12:20352039

Xu X, Zhang N, Zhao D, Liu C (2021) The effect of trade openness on the relationship between agricultural technology inputs and carbon emissions: evidence from a panel threshold model. Environ Sci Pollut Res 28:9991-10004
Yaghoubi J, Yazdanpanah M, Komendantova N (2019) Iranian agriculture advisors' perception and intention toward biofuel: green way toward energy security, rural development and climate change mitigation. Renew Energy 130:452-459

Yang J, Huang Z, Zhang X, Reardon T (2013) The rapid rise of crossregional agricultural mechanization services in China. Am J Agric Econ 95:1245-1251

Yin P, Fang X, Yun Y (2009) Regional differences of vulnerability of food security in China. J Geogr Sci 19(5):532-544

$\mathrm{Yu} \mathrm{J,} \mathrm{Wu} \mathrm{J} \mathrm{(2018)} \mathrm{The} \mathrm{sustainability} \mathrm{of} \mathrm{agricultural} \mathrm{development} \mathrm{in}$ China: the agriculture-environment nexus. Sustainability 10(6): 1776

Zhao D, Arshad M, Li N, Triantafilis J (2021) Predicting soil physical and chemical properties using vis-NIR in Australian cotton areas. Catena 196:104938

Zhi J, Gao J (2009) Analysis of carbon emission caused by food consumption in urban and rural inhabitants in China. Prog Geogr 3: $429-434$

Publisher's note Springer Nature remains neutral with regard to jurisdictional claims in published maps and institutional affiliations. 